\title{
Characterization of complexation of PVP copolymer with DNA
}

\author{
Lifen Zhang ${ }^{a}$, Yong Liang ${ }^{b, c}$, Lingzhi Meng ${ }^{a *}$ and Chang Wang ${ }^{b}$
}

\begin{abstract}
Interactions of amphiphilic copolymer poly( $N$-vinylpyrrolidone-co- $N$-t-Boc- tryptophanamido- $N^{\prime}$-methacrylthiourea) [P(NVP-co-TrpAMT)] and poly(N-vinylpyrrlidone) (PVP) with DNA were studied with the aim to understand the difference in their complexation efficiencies when considered as a potential non-viral delivery vector. Fluorescence spectroscopy, ethidium bromide (EB) quenching, $\zeta$ potential measurement, and agarose gel electrophoresis were all carried out in Tris- $\mathrm{HCl}(\mathrm{pH}$ 7.4) solution to assess the degree of interaction between the (co)polymers P(NVP-co-TrpAMT) and DNA. All of these measurements show that the high affinity of the copolymer for DNA can be demonstrated. We also found that P(NVP-Co-TrpAMT)-I (PVP/PTrpAMT molar ratio was 100:2.88) exhibited a high DNA cleavage activity and induced the supercoiled form of the plasmid cleavage in the nicked and linear forms.

Moreover, P(NVP-co-TrpAMT)-I exhibited stronger affinity for DNA than PVP and P(NVP-co-TrpAMT)-II (PVP/ PTrpAMT molar ratio of 100:6.35). This phenomenon is believed to be related to the structure of TrpAMT and the hydrophobic nature of the copolymer. P(NVP-co-TrpAMT)-II with higher hydrophobic segments creates a strong hydrophobic interaction and induces a steric barrier which hinders their complexation with DNA. The study reveals important information about the inner mechanisms involved in the interaction of the PVP copolymer with DNA, which aids in the design of novel efficient non-ionic gene carriers. Copyright (c) 2008 John Wiley \& Sons, Ltd.
\end{abstract}

Keywords: PVP copolymer; DNA interaction; amphiphiles; fluorescence; water-soluble polymer

\section{INTRODUCTION}

Recently, non-viral gene therapy based on DNA complexes with polymers has attracted significant attention. ${ }^{[1-4]}$ One major approach in the principle of non-viral gene delivery lies in the condensation of DNA in the presence of synthetic polycations. ${ }^{[5-8]}$ Despite the high ability of complexation, cationic polymers usually exhibit highly toxic properties and low transfection efficiency. ${ }^{[9]}$

An alternative approach for gene delivery in evaluating non-ionic amphiphilic polymers has been found to promote gene delivery in tissues such as skeletal and cardiac muscle. ${ }^{[4,10]}$ Novel pluronic triblock copolymer PEO-PPO-PEO and biodegradable polymer PEG-PLGA-PEG can increase the expression of plasmid DNA in skeletal muscle in mice. ${ }^{[4,10]}$ Non-charged, nontoxic, and biocompatible hydrophilic polymer PVP ${ }^{[11]}$ has the same properties as poly (ethylene glycol) (PEG) and has been applied in various drug delivery systems, including microspheres, nanoparticles, liposomes, and polymer conjugates. ${ }^{[12-16]}$ Recently, PVP, as a potential booster of the gene expression using the naked DNA, was explored, and the results demonstrated that PVP can enhance the gene expression of the naked DNA in tissues. ${ }^{[17-19]}$ These non-ionic polymers improve the gene expression most likely through non-condensing DNA and facilitate the transport of the gene into the cell. ${ }^{[9]}$

In a previous study, we demonstrated that amphiphilic PVP copolymer P(NVP-co-TrpAMT) can destabilize the double strands (dsDNA) and enhance the amplification of the polymerase chain reaction $(P C R) .{ }^{[20]}$ To address the challenging application of amphiphilic PVP copolymer/DNA complexes in the gene therapy and to design efficient carrier rationally, it is essential to understand the interaction mechanism between the copolymer and DNA. As reported, ethidium bromide (EB) displacement, ${ }^{[21]}$ electrophoresis, ${ }^{[22]}$ dynamic light scattering, ${ }^{[22]}$ UV spectroscopy, ${ }^{[23]}$ atomic force and transmission electron microscopies $^{[24]}$ and $\zeta$ potential ${ }^{[21]}$ have already been used to characterize the interaction of copolymer with DNA in solution.

The aim of this work is to explore the interaction of copolymer $\mathrm{P}$ (NVP-co-TrpAMT) containing different amounts of hydrophobic segments, with DNA via fluorescence spectroscopy, EB quenching, $\zeta$ potential measurements, and agarose gel electrophoresis, and then to compare their behaviors with that of PVP. The information obtained helps to understand the interaction mechanism of amphiphilic copolymer with DNA. Furthermore, it might provide a useful technique to design novel efficient non-ionic gene carrier rationally.

\footnotetext{
* Correspondence to: L. Meng, Department of Chemistry, Wuhan University, Wuhan 430072, P.R. China.

E-mail: Izhmeng@whu.edu.cn

a L. Zhang, L. Meng

Department of Chemistry, Wuhan University, Wuhan 430072, P.R. China

b Y. Liang, C. Wang

State Key Laboratory of Environmental Chemistry and Ecotoxicology, Research Center for Eco-Environmental Sciences, Chinese Academy of Sciences, P.O. Box 2871, Beijing 100085, P.R. China

c Y. Liang

Cancer Institute of Jianghan University, School of Medicine and Life Science, Jianghan University, Wuhan, 430056, P.R. China
} 


\section{EXPERIMENTAL}

\section{Materials}

$\mathrm{N}$-vinylpyrrolidone (NVP) (Acros Organics, 99\%) was purified by distillation under reduced pressure to remove the inhibitors prior to use. The hydrophobic monomer $N$-t-Boc-tryptophanamido$N^{\prime}$-methacryl thiourea (TrpAMT) (Scheme 1) was prepared as previously described. ${ }^{[20]}$ Dioxane (Shanghai Chemical Reagents Co.) was purified by distillation before use. Azobis(isobutyronitrile) (AIBN, Shanghai) was recrystallized from methanol. EB (Sigma Co.), Herring Sperm DNA (Sigma Co.) and supercoiled plasmid DNA (pBR322, 4.4 kb) (Sino-American Biotechnology Co.) were used as received without further purification. Solvents were of reagent grade.

\section{Synthesis of PVP and amphiphilic copolymer P(NVP-co-TrPAMT)}

PVP and copolymers P(NVP-co-TrpAMT)-I, -II with different molar ratios of NVP to TrpAMT (Table 1) were prepared by the following typical procedure described in the previous study. ${ }^{[20]}$ The chemical structures of the monomers such as NVP and TrpAMT and the obtained (co)polymers are shown in Scheme 1. Solution of the monomers and AIBN in dioxane was added into a Schlenk tube and sealed with a rubber septum. The tube was degassed at room temperature with nitrogen for $30 \mathrm{~min}$ and was then immersed in an oil bath that was preheated to $60^{\circ} \mathrm{C}$. After $24 \mathrm{hr}$, the mixture was cooled to room temperature. The polymer was precipitated from dioxane into diethyl ether, then purified further by two additional precipitations from chloroform into diethyl ether, and dried under vacuum at room temperature.

\section{Analysis}

${ }^{1} \mathrm{H}$ NMR spectra were recorded on a Varian Mercury VX-300 MHz spectrometer (USA). Gel permeation chromatography-multiangle laser light scattering (GPC-MALLS) analysis was carried out on DAWN ${ }^{\mathbb{R}}$ DSP multi-angle laser photometer with a pump P100 (Thermo Seperation Products, San Jose, USA) equipped with TSK-GEL G6000 PWXL with a G4000 PWXL column $(7.8 \mathrm{~mm} \times 300 \mathrm{~mm})$ for DMF, and a differential refractive index detector (RI-150) at $25^{\circ} \mathrm{C}$
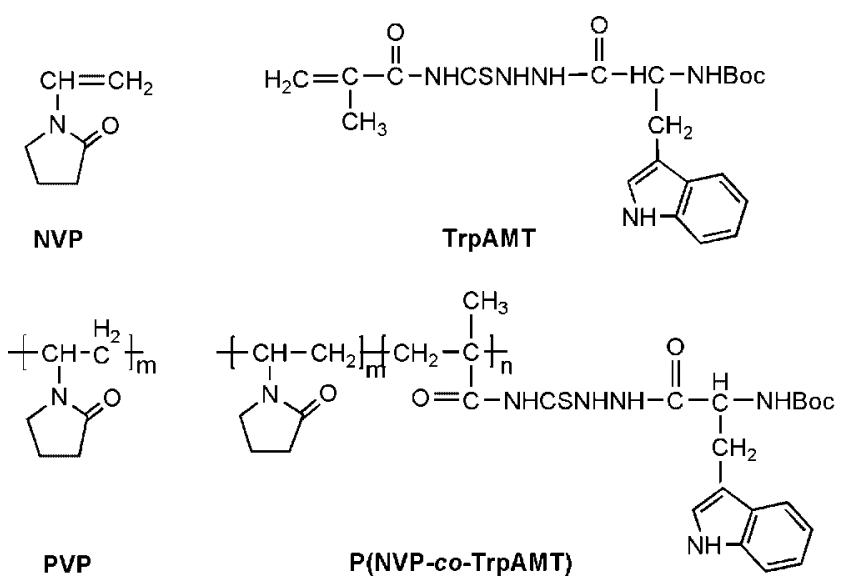

Scheme 1. Chemical structures of the monomers and (co)polymers.
$\mathrm{P}$ (NVP-co-TrpAMT) fluorescence titration was performed on a steady-state fluorescence spectrometer (Shimadzu RF-5301PC spectrometer, Japan) at room temperature in Tris- $\mathrm{HCl}$ buffer (pH 7.4). The copolymer solution $(3.5 \mathrm{ml} ; 1 \mathrm{mg} / \mathrm{ml})$ was added with increase in quantities of DNA solution $(1.0 \mathrm{mg} / \mathrm{ml})$ and the final concentrations of DNA ranged from 0 to $0.013 \mathrm{mg} / \mathrm{ml}$. The emission spectra of P(NVP-co-TrpAMT)-I and II were measured in the range of $300-500 \mathrm{~nm}$ with excitation at $295 \mathrm{~nm}$. The emission and excitation slit widths were 10 and $5 \mathrm{~nm}$, respectively.

The EB quenching experiments were determined by the steady-state fluorescence spectrometer. The EB-DNA complexation solution $([E B]=0.25 \mu \mathrm{g} / \mathrm{ml}$ and $[D N A]=2 \mu \mathrm{g} / \mathrm{ml}$ ) was made by mixing $\mathrm{EB}(62.4 \mu \mathrm{l}, 0.4 \mathrm{mg} / \mathrm{ml}$ in Tris- $\mathrm{HCl}$ buffer) and Herring Sperm DNA ( $100 \mathrm{ml}, 2 \mu \mathrm{g} / \mathrm{ml}$ in Tris- $\mathrm{HCl}$ buffer). Each $3 \mathrm{ml}$ of the EB-DNA solution was added to different volumes of the (co)polymer solution $(2 \mathrm{mg} / \mathrm{ml})$. The final concentrations of the (co)polymer ranged from 0 to $0.33 \mathrm{mg} / \mathrm{ml}$. The samples were stirred overnight and stored at $25^{\circ} \mathrm{C}$. The $3 \mathrm{ml}$ mixture solution was transferred to a quartz vessel, and the EB fluorescence values were measured $\left(\lambda_{\mathrm{ex}}=519 \mathrm{~nm}, \lambda_{\mathrm{em}}=596 \mathrm{~nm}\right)$. The emission and excitation slit widths were 5.0 and $5.0 \mathrm{~nm}$, respectively. The fluorescence readings for every sample were conducted in triplicate.

The $\zeta$ potential measurements were performed using a Zetamaster 5002 particle electrophoresis analyzer (Malvern Nano ZS90 Instruments, Ltd., UK) equipped with a He-Ne laser $(633 \mathrm{~nm}$, $5 \mathrm{~mW})$ and a standard electrophoresis cell of quartz $(5 \mathrm{~mm} \times$ $2 \mathrm{~mm}$ ). The (co)polymer/DNA complexes were prepared using different (co)polymer concentrations and plasmid pBR322 in the $0.1 \mathrm{M} \mathrm{NaCl}$ solution, which were previously filtered through $0.2 \mu \mathrm{m}$ nylon filters (Millipore). The DNA concentration in the solution was held constant at $0.2 \mu \mathrm{g} / \mathrm{ml}$ whereas the concentration of (co)polymer was varied to cover a wide range of (co)polymer/DNA weight ratios.

The binding ability of the (co)polymers to DNA was also investigated by electrophoresis on agarose gel. The concentration of supercoiled plasmid DNA (pBR 322) was diluted in Tris-HCl buffer ( $\mathrm{pH} 7.4$ ) to $100 \mu \mathrm{g} / \mathrm{ml}$. The (co)polymer solution and DNA solution were then mixed thoroughly at the weight ratio of 30:1 in Tris- $\mathrm{HCl}$ buffer and incubated at $37^{\circ} \mathrm{C}$ for different time intervals. Tris- $\mathrm{HCl}$ buffer $(\mathrm{pH}$ 7.4) was added to yield the final volume $(10 \mu \mathrm{l})$, whereas free DNA served as a control. After incubation, an aliquot $(8 \mu \mathrm{l})$ of the solution was mixed with bromophenol blue-glycerol solution $(1 \mu \mathrm{l})$ and loaded to run on a $1.0 \%$ agarose gel $(100 \mathrm{v}, 35 \mathrm{~min})$. The DNA markers were also electrophoresed. DNA in the gels was stained with EB, visualized, and photographed using a gel imaging system (UVP). The intensity of the EB-stained band was determined by the gel analysis system (Jieda Tech, Nanjing) using the auto background subtraction mode to remove background signals.

\section{RESULTS AND DISCUSSION}

\section{Synthesis and characterization of the (co)polymers}

PVP and amphiphilic copolymer P(NVP-co-TrpAMT)-I, II were prepared by the radical polymerization of $N$-vinylpyrrolidone and hydrophobic functional monomer TrpAMT with hydrophilic PVP in dioxane using AIBN as an initiator, respectively. The ${ }^{1} \mathrm{H}$ NMR spectra of PVP showed that the characteristic peaks corresponding to the vinyl groups of monomers between 4.8 and $6.5 \mathrm{ppm}$ 
Table 1. Results of polymerization and characterization

\begin{tabular}{|c|c|c|c|c|c|}
\hline \multirow[b]{2}{*}{ (Co)polymer } & \multirow[b]{2}{*}{$m / n^{a}$} & \multirow[b]{2}{*}{$m / n^{b}$} & \multicolumn{2}{|l|}{ Conv. } & \multirow[b]{2}{*}{$M_{\mathrm{w}} / M_{\mathrm{n}}^{\mathrm{c}}$} \\
\hline & & & $\%$ & $M_{\mathrm{n}}{ }^{\mathrm{c}}$ & \\
\hline P(NVP-co-TrpAMT)-I & $100: 1$ & $100: 2.88$ & 80.2 & 11,550 & 1.46 \\
\hline P(NVP-co-TrpAMT)-II & $100: 1.25$ & $100: 6.35$ & 76.5 & 35,520 & 1.38 \\
\hline PVP & 100:0 & 100:0 & 80.5 & 8,000 & 1.21 \\
\hline
\end{tabular}

disappeared completely in $\mathrm{CDCl}_{3}$. For P(NVP-co-TrpAMT)-I, the proton signals of hydrophobic segments indole cyclic groups appeared at the chemical shifts of $7.0 \sim 7.6 \mathrm{ppm}$. The structure of $\mathrm{P}\left(\mathrm{NVP}\right.$-co-TrpAMT)-II was also confirmed by ${ }^{1} \mathrm{H}$ NMR spectra in $\mathrm{CDCl}_{3}$, and the signals of its spectra were quite similar to that of P(NVP-co-TrpAMT)-I. ${ }^{[20]}$ The observation confirmed that PVP and $\mathrm{P}$ (NVP-co-TrpAMT) were successfully obtained. The molecular weights of the (co)polymers evaluated by GPS-MALLS and their composition obtained by the analysis of ${ }^{1} \mathrm{H}$ NMR spectra are listed in Table 1.

\section{The interaction of the (co)polymer with DNA}

Fluorescence spectroscopy measurements

Figure 1 shows the relative fluorescence intensity of the copolymer P(NVP-co-TrpAMT) in the presence of DNA. The fluorescence from the tryptophan residues in the copolymer exhibits a specific fluorescence in aqueous solution $\left(\lambda_{\mathrm{ex}}\right.$ max $\left.295 \mathrm{~nm}, \lambda_{\mathrm{em}}, \max 360 \mathrm{~nm}\right)$. The relative fluorescence intensity of P(NVP-co-TrpAMT)-I and -II in the presence of DNA was decreased linearly with increase in DNA concentration (Fig. 1). The fluorescence intensity of P(NVP-co-TrpAMT)-I decreased by

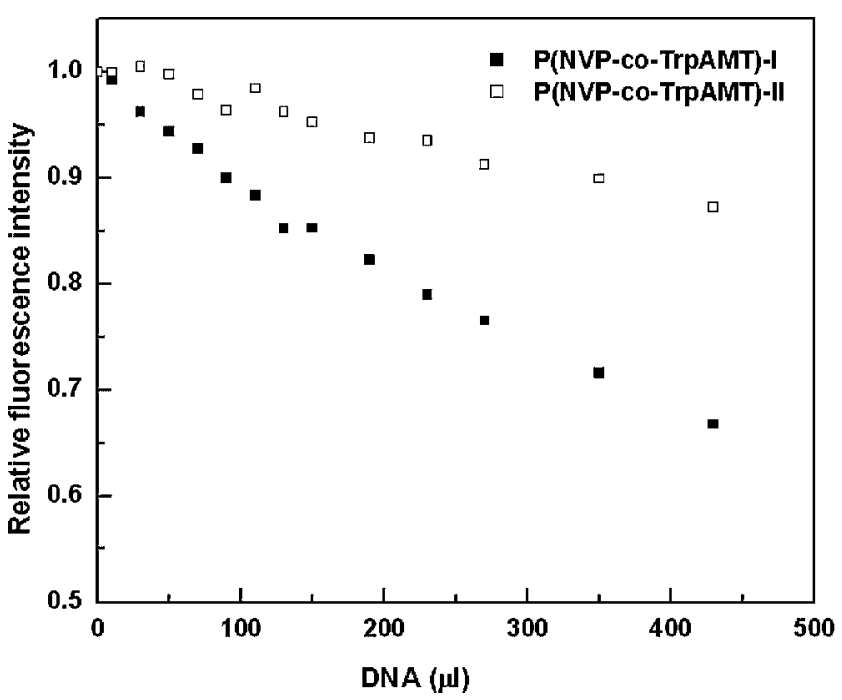

Figure 1. Relative fluorescence intensity of P(NVP-co-TrpAMT)-I (solid squares) and P(NVP-co-TrpAMT)-II (open squares) versus volume of DNA added.
28.4\%, much more than that of P(NVP-co-TrpAMT)-II which decreased by $10.1 \%$ when the volume of DNA added was $350 \mu \mathrm{l}$ (the weight ratio of the copolymer/DNA was 86:1). The copolymer displayed a remarkable change in the fluorescence in the presence of DNA, indicating a significant interaction of the copolymer with DNA. Also the degree of the interaction is related to the contents of the hydrophobic segments in the copolymer.

The significantly fluorescence responsive behavior can be explained by the environment change of the hydrophobic chromophore when DNA was added to the copolymer solution. The intrinsic fluorescence of oligopeptides containing tryptophan is quenched substantially upon binding DNA. ${ }^{[25-27]}$ Akanchha et al. ${ }^{[27]}$ have studied the interaction of a tetrapeptide, KWGK-otBut, with duplex of the chosen 21-mer GC-rich oligonucleotide sequence using fluorescence spectra. The fluorescence quenching of KWGK-otBut with the addition of duplex can be attributed to the intercalating and stacking interactions between tryptophan residues and $\mathrm{GC}$ regions of the above sequence. According to our results, with the addition of DNA, the hydrophobic chromophore of copolymer most likely interacted with DNA via aromatic stacking, intercalation, and hydrogen binding interactions, which in turn resulted in the intrinsic fluorescence quenching of the copolymer progressively.

However, with the increase in the molar ratio of hydrophobic segments to hydrophilic segments, the quenching degree of P(NVP-co-TrpAMT)-II was reduced. This suggests that the contents of the hydrophobic segments in the copolymer are of crucial importance for the interaction of the copolymer with DNA. P(NVP-co-TrpAMT)-I can self-aggregate into micelle which can be verified by the transmission electron microscopy image. ${ }^{[20]}$ The high contents of the PTrpAMT segments in the copolymer caused the strong hydrophobic interaction in the micelle, making the interaction with DNA more difficult. Also, the higher hydrophobic contents in the copolymer may create a steric barrier, to some extent hindering DNA complexation, and decreasing the ability of interacting with DNA.

\section{$E B$ quenching experiments}

Intercalation of EB into the DNA can cause a remarkable increase in the fluorescence of EB. ${ }^{[28]}$ The ability of the copolymer to bind to DNA was monitored by recording the fluorescence of EB-DNA complex. ${ }^{[29]}$ The addition of cationic liposomes which are able to displace EB from the EB-DNA complex results in the quenching of the fluorescence. ${ }^{[30]}$ To further explore the interaction of 


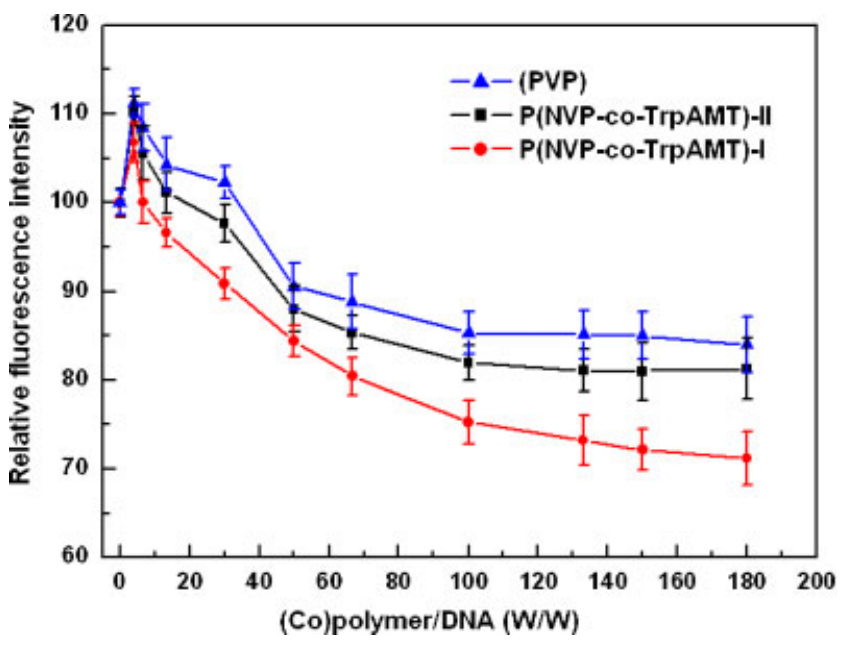

Figure 2. Relative fluorescence intensity of EB-DNA fluorescence versus the (co)polymers/DNA ratio (w/w). Error bar corresponding to standard derivation ( $n=3$ measurements). This figure is available in colour online at www.interscience.wiley.com/journal/pat

copolymer P(NVP-co-TrpAMT) with DNA, the fluorescence spectra of the EB-DNA complex in the presence of the copolymers were also monitored.

Figure 2 shows the relative fluorescence intensity of the EB-DNA complex in the presence of PVP or P(NVP-co-TrpAMT). The quenching of the EB-DNA complex fluorescence was observed in the presence of PVP or P(NVP-co-TrpAMT). The degree of the EB quenching depended on both the (co)polymer/ DNA weight ratio and the contents of the hydrophobic chains in the copolymer. The higher quenching of the EB-DNA complex by P(NVP-co-TrpAMT)-I compared to PVP and P(NVP-co-TrpAMT)-II was observed. The maximum reduction of relative fluorescence intensity reached $66.7 \%$ at $\mathrm{P}(\mathrm{NVP}-\mathrm{co}-\mathrm{TrpAMT})-\mathrm{I} / \mathrm{DNA}$ weight ratio of 133:1, suggesting a strong interaction of the copolymer $P(N V P-c o-T r p A M T)-I$ with DNA. Above the ratio value, the fluorescence intensity almost had no further decline, implying that the interaction of the (co)polymers with DNA tended to achieve equilibrium.

Contrary to the cationic copolymers-DNA complexes formed via strong electronic interaction, the non-ionic copolymers can interact with DNA through multiple hydrogen bonding and hydrophobic interactions. ${ }^{[17]}$ PVP polymers possess a positive charge and form a stronger hydrogen bonding with DNA in water below $\mathrm{pH}$ 5.5. ${ }^{[31]}$ Mumper et al. ${ }^{[17]}$ demonstrated that the reduction of EB-DNA complex fluorescence intensity by PVP aqueous solution at $\mathrm{pH} 4.0$ reached $60 \%$, suggesting that the quenching may occur when PVP forms a ternary complex with DNA and EB by the electrostatic, hydrogen bonding, and hydrophobic interactions. In our work, the slight quenching of the EB fluorescence intensity by PVP in Tris-HCl buffer $(\mathrm{pH} 7.4)$ suggests that PVP interacts with DNA mainly via hydrogen bonding and hydrophobic interactions. Whereas the copolymer exhibits a significant quenching of the EB fluorescence compared to PVP, mostly due to the complicated interactions of tryptophan residues with DNA, such as hydrogen bonding, stacking, and intercalating interaction. With increase in the hydrophobic contents of the copolymer, the ability to quench EB fluorescence decreased. This is most probably due to a balance between the hydrophobic segments effect that tends to quench the $E B$ fluorescence by the intercalation of the indole residues in the hydrophobic chain into DNA, and the steric structure of P(NVP-co-TrpAMT)-II which contains higher hydrophobic contents to a large extent limits the interaction with DNA.

\section{$\zeta$ Potential determination}

To evaluate the effect of the (co)polymers on the surface charge of DNA, the $\zeta$ potentials of PVP/DNA and P(NVP-co-TrpAMT)/DNA complexes at various weight ratios in salt solution are shown in Fig. 3. The effect of increasing P(NVP-co-TrpAMT)-I/DNA weight ratio on the charge of $\mathrm{P}(\mathrm{NVP}-\mathrm{co}-\mathrm{TrpAMT})-\mathrm{I} / \mathrm{DNA}$ complex is very pronounced, as compared to that of the PVP/DNA and P(NVP-co-TrpAMT)-II/DNA complexes under the same conditions. The charge of the P(NVP-co-TrpAMT)-I/DNA complex became less negative with increase in the weight ratio of the copolymer to DNA, and tended to reach equilibrium at their weight ratio of $100: 1$. It is interesting to note that the potential of P(NVP-co-TrpAMT)-I/DNA complex tended to be electroneutral even when the weight ratio was further increased above 100:1.

The negative reduction of $\mathrm{P}(\mathrm{NVP}$-co-TrpAMT)/DNA complexes with increase in the copolymer indicates that the copolymer can significantly modify the DNA surface properties. On the basis of the fact that the $\zeta$ potential of PVP is approximately $0 \mathrm{mV}$ in salt solution, ${ }^{[17]}$ the interaction modes between the copolymer and DNA can include hydrogen bonding, hydrophobic interaction, and indole residues' stacking. The interactions, in turn, promote shielding of the negatively charged phosphate groups, resulting in an increase in the surface charge of DNA. In addition, P(NVP-co-TrpAMT)-II with high hydrophobic segments cannot induce the efficient modification of the DNA surface most likely due to the negative effect of the strong hydrophobic steric barrier on the interaction of the copolymer with DNA.

\section{Agarose gel electrophoresis}

Gel electrophoresis assays were performed to investigate the ability of the copolymers to interact with DNA. The widely used assay with pBR322 supercoiled DNA was employed. Figure 4 shows that the copolymer P(NVP-co-TrpAMT)-I cleaves DNA

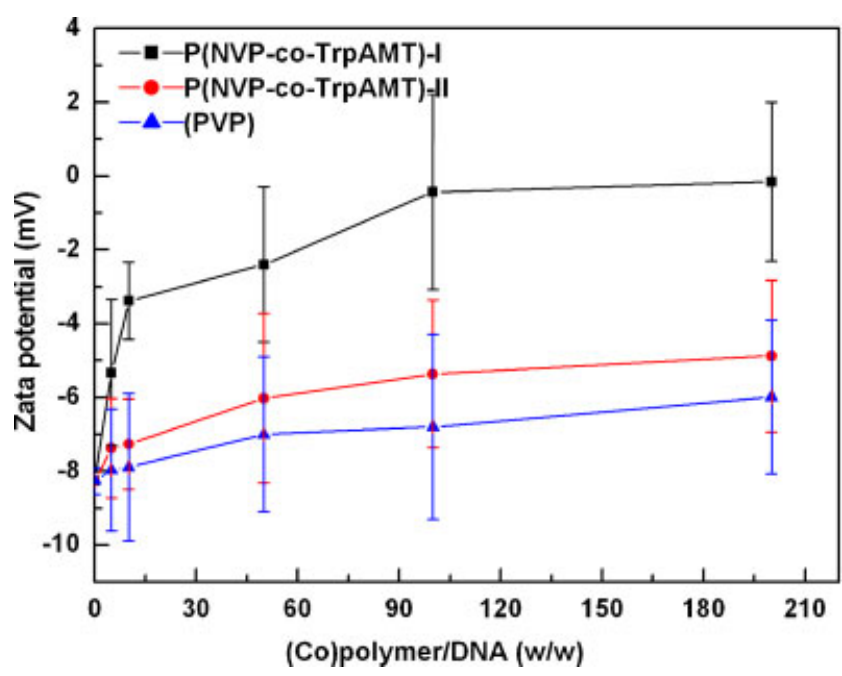

Figure 3. The $\zeta$ potential versus the weight ratio of (co)polymers/DNA in $0.1 \mathrm{M} \mathrm{NaCl}$ with DNA $(0.2 \mu \mathrm{g} / \mathrm{ml})$. Results are reported as mean \pm standard derivation ( $n=3$ measurements). This figure is available in colour online at www.interscience.wiley.com/journal/pat 
(a)

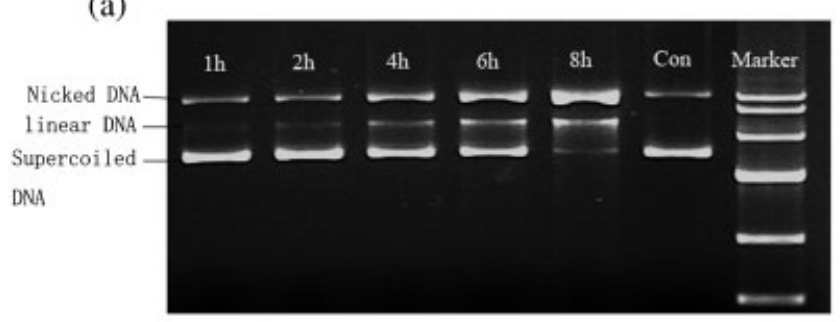

(b)

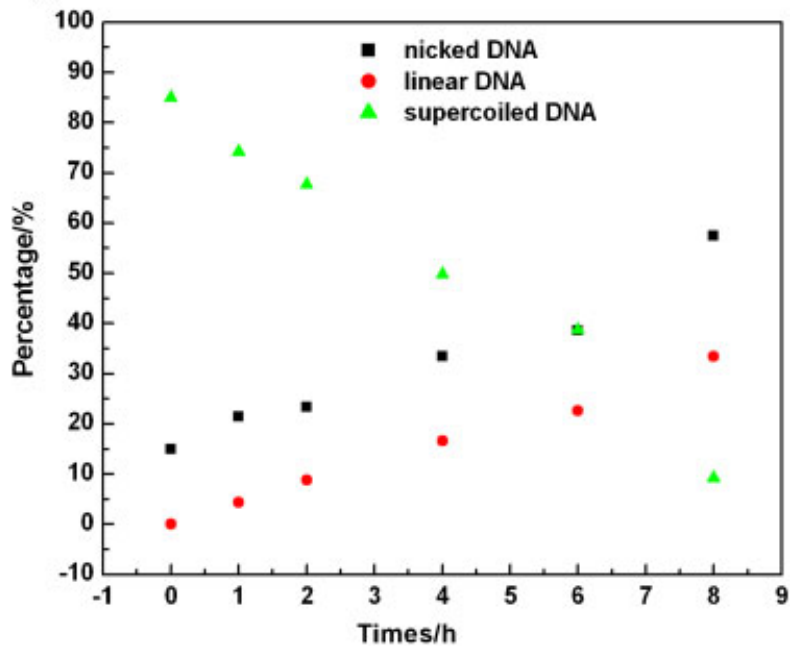

Figure 4. (a) Cleavage of supercoiled DNA (triangle) was incubated for different times for the weight ratio 30:1 of P(NVP-Co-TrpAMT)-I to DNA to obtain nicked (square) and linear (circle) forms at $37^{\circ} \mathrm{C}$. (b) Calculated intensities of the DNA gel areas for three forms at different times for (a). This figure is available in colour online at www.interscience.wiley.com/ journal/pat

(supercoiled form) to give both nicked and linear forms of the plasmid. The DNA control had a band corresponding to the supercoiled form and fainter bands for the naked form. The band corresponding to the supercoiled form decreased with increase in incubation time with a concomitant increase in nicked and linear forms (Fig. 4a), suggesting the high DNA-cleavage ability of P(NVP-co-TrpAMT)-I. PVP and P(NVP-co-TrpAMT)-II exhibits a relatively weak ability to cleave the supercoiled DNA plasmid under the same conditions (Figure not shown), indicating the contents of hydrophobic chain in the PVP copolymer plays an important role in the expression of DNA-cleaving activity. Furthermore, no smear appearing in DNA bands was observed, suggesting that the covalent bonds of the plasmid strands were not broken.

All the three forms of the plasmid were presented on the gel at the same time, which is a strong qualitative indication of a direct double strand DNA cleavage pathway. ${ }^{[32]}$ According to the image analysis, a significantly more increase in the percentage of the nicked form than that of the linear form within $4 \mathrm{hr}$ of incubation was observed (Fig. 4b). When the incubation time was further prolonged, a pronounced increase in the percentage of the linear form was observed in the system. The results can be explained by the fact that when two strand breaks are too distant in the plasmid sequence, the hydrogen bonding network between the PVP copolymer and plasmid can limit the linearization of the plasmid, and thus obtain the high percentage of the nicked form.

The gel electrophoresis results demonstrated that the interaction of P(NVP-co-TrpAMT)-I with DNA can induce the topology change of the plasmid, but not degrade DNA. It has been reported that intracellular degradation of the DNA significantly limits the gene transfer efficiency. ${ }^{[33]}$ Several studies on non-viral gene transfer were performed with PVP which can encapsulate DNA and protect it from intracellular degradation, ${ }^{[34]}$ and with naked plasmid ${ }^{[35,36]}$ which are known to be less susceptible to intracellular degradation. Thus, the PVP copolymer $\mathrm{P}$ (NVP-co-TrpAMT) as a gene carrier has a potential application for gene delivery. Whether or not such a non-viral carrier will significantly improve the transfection remains to be elucidated.

\section{CONCLUSIONS}

Copolymer P(NVP-co-TrpAMT) combines the biocompatible PVP and hydrophobic PTrpAMT segments with strong affinity for DNA. Both intrinsic fluorescence and EB-DNA complex fluorescence quenching studies revealed that the copolymers can interact with DNA efficiently. The surface $\zeta$ potential of DNA was also modified upon increasing of the copolymer. P(NVP-co-TrpAMT)-I exhibited high activities toward the cleavage of supercoiled plasmid DNA to give nicked and linear DNA forms. The results showed that the copolymer P(NVP-co-TrpAMT) exhibited high affinity for DNA. Taking the above results into account, we believe it is likely that the mechanism interaction of the DNA with copolymer $\mathrm{P}(\mathrm{NVP}-\mathrm{co}$-TrpAMT) is highly dependent on the composition of the synthetic amphiphilic copolymer. Although TrpAMT segments exhibit the ability of binding DNA strongly, the higher hydrophobic contents tend to sterically hinder the DNA complexation process, which can explain the lower affinity of copolymer P(NVP-co-TrpAMT)-II for DNA.

\section{Acknowledgements}

We thank the China National Natural Science Foundation (grant no. 20474044) and the Research Fund for the Doctoral Program of Higher Education (2006) for their financial support.

\section{REFERENCES}

[1] L. C. Smith, J. Duguid, M. S. Wadhwa, M. J. Logan, C. H. Tung, V. Edwards, J. T. Sparrow, Adv. Drug Deliv. Rev. 1998, 3, 115-131.

[2] L. Bromberg, S. Deshmukh, M. Temchenko, L. lourtchenko, V. Alakhov, C. Alvarez-Lorenzo, R. Barreiro-Iglesias, A. Concheiro, T. A. Hatton, Bioconjug. Chem. 2005, 1, 626-633.

[3] A. Vila, A. Sánchez, C. Pérez, M. J. Alonso, Polym. Adv. Technol. 2003, 1, 851-858.

[4] C. W. Chang, D. H. Choi, W. J. Kim, J. W. Yockman, L. V. Christensen, Y. H. Kim, S. W. Kim, J. Control. Release 2007, 11, 245-253.

[5] S. C. De Smedt, J. Demeester, W. E. Hennink, Pharm. Res. 2000, 1, 113-126.

[6] C. L. Gebhart, A. V. Kabanov, J. Control. Release 2001, 7, 401-416.

[7] E. Wagner, Pharm. Res. 2004, 2, 8-14.

[8] L. Y. Qiu, H. B. You, Biomaterials 2007, 2, 4132-4142.

[9] R. A. Jones, M. H. Poniris, M. R. Wilson, J. Control. Release 2004, 9, 379-391.

[10] A. V. Kabanov, P. Lemieux, S. Vinogradov, V. Alakhov, Adv. Drug Deliv. Rev. 2002, 5, 223-233.

[11] V. P. Torchilin, T. S. Levchenko, K. R. Whiteman, Biomaterial 2001, 2, 3035-3044.

[12] M. Moneghini, D. Voinovich, F. Princivalle, L. Magarotto, Pharm. Dev. Technol. 2000, 5, 347-353.

[13] D. Sharma, T. P. Chelvi, J. Kaur, K. Chakravorty, A. De TK, Maitra, R. Ralhan, Oncol. Res. 1996, 8, 281-286. 
[14] V. P. Torchilin, M. I. Shtilman, V. S. Trubetskoy, K. Whiteman, A. M. Milstein, Biochim. Biophys. Acta 1994, 119, 181-184.

[15] H. Kamada, Y. Tsutsumi, Y. Yamamoto, T. Kihira, Y. Kaneda, Y. Mu, H. Kodaira, S. I. Tsunoda, S. Nakagawa, T. Mayumi, Cancer Res. 2000, 6, 6416-6420.

[16] A. J. M. D'souza, R. L. Schowen, E. M. Topp, J. Control. Release 2004, 9, 91-100.

[17] R. J. Mumper, J. Wang, S. L. Klakamp, H. Nitta, K. Anwer, F. Tagliaferri, A. P. Rolland, J. Control. Release 1998, 5, 191-203.

[18] S. K. Mendiratta, A. Quezada, M. Matar, N. M. Thull, J. S. Bishop, J. L. Nordstrom, F. Pericle, Hum. Gene Ther. 2000, 1, 1851-1862.

[19] X. Y. Sun, H. Q. Qiao, H. C. Jiang, X. T. Zhi, F. J. Liu, J. L. Wang, M. Liu, D. N. Dong, J. R. Kanwar, R. A. Xu, G. W. Krissansen, Cancer Gene Ther. 2005, 1, 35-45.

[20] L. F. Zhang, Y. Liang, L. Z. Meng, X. J. Lu, Y. H. Liu, Chem. Biodivers. 2007, 4, 163-174.

[21] C. Alvarez-Lorenzo, R. Barreiro-lglesias, A. Concheiro, L. lourtchenko, V. Alakhoe, L. Bromberg, M. Temchenko, S. Deshmukh, T. A. Hatton, Langmuir 2005, 2, 5142-5148.

[22] A. G. Gómez-Valadés, M. Molas, A. Vidal-Alabró, J. Bermúdez, R. Bartrons, J. C. Perales, J. Control. Release 2005, 10, 277-291.

[23] S. Katayose, K. Kataoka, J. Pharm. Sci. 1998, 8, 160-163.

[24] B. J. Rackstraw, A. L. Martin, S. Stolnik, Lamgmuir 2001, 1, 3185-3193.
[25] D. P. Mascotti, T. M. Lonhman, Biochemisty 1993, 3, 10568-10579.

[26] S. Padmanabhan, W. T. Zhang, M. W. Capp, Biochemistry 1997, 3, 5193-5206.

[27] A. A. Jain, M. R. Rajeswari, Biochim. Biophys. Acta, Gen. Subj. 2003, 162, 154-154.

[28] T. K. Bronich, H. K. Nguyen, A. Eisenberg, A. V. Kabanov, J. Am. Chem. Soc. 2000, 12, 8339-8343.

[29] L. Veron, A. Ganee, M. T. Charreyre, C. Pichot, T. Delair, Macromol. Biosci. 2004, 4, 431-444.

[30] Y. Xu, F. C. Szoka, Biochemistry 1996, 3, 5616-5623.

[31] V. Buehler, Kollidon: Polyvinypyrrolidone for the Pharmaceutical Industry. BASF, 1993, 39-42.

[32] F. Mancin, P. Scrimin, P. Tecilla, U. Tonellato, Chem. Commun. 2005, 2, $2540-2548$

[33] J. Glasspool-Malone, P. R. Steenland, R. J. McDonald, R. A. Sanchez, T. L. Watts, J. Zabner, R. W. Malone, J. Gene Med. 2002, 4, 323332.

[34] K. Cifti, R. J. Levy, Int. J. Pharm. 2001, 21, 81-92.

[35] T. Anada, R. Karinaga, K. Koumoto, M. Mizu, T. Nagasaki, Y. Kato, K. Taira, S. Shinkai, K. Sakurai, J. Control. Release 2005, 10, 529-539.

[36] M. A. Van der Aa, G. A. Koning, C. d'Oliveira, R. S. Oosting, K. J. Wilschut, W. E. Hennink, D. J. Crommelin, J. Gene Med. 2005, 7, 208-217. 